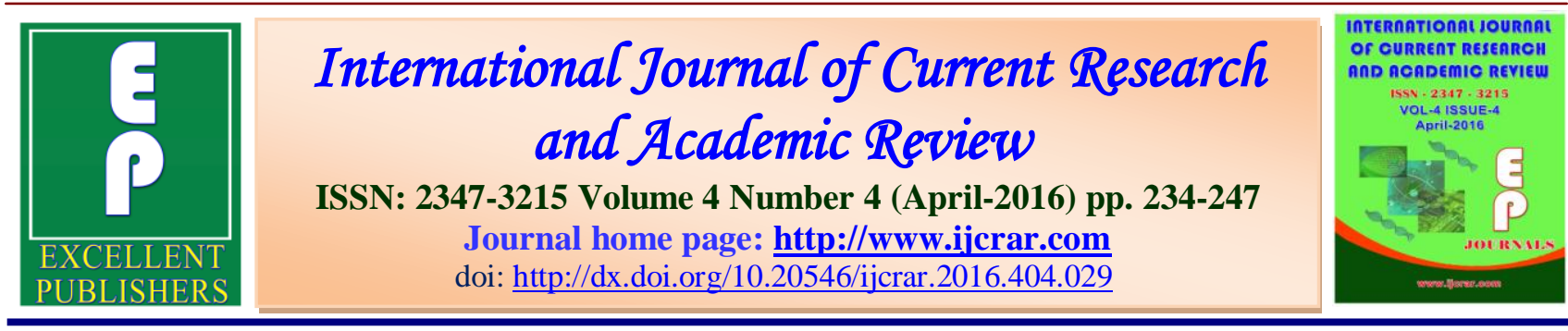

\title{
Determination of serum level of Vitamin D in hospitalized patients with respiratory infections in infectious disease wards of Tabriz
}

\author{
Zhinous Bayatmakoo ${ }^{1,2}$, Fatemeh Ravanbakhs Ghavghani ${ }^{1,2}$ and Haleh Rezaee $^{1,3 *}$ \\ ${ }^{1}$ Infectious and Tropical Diseases Research center, Tabriz University of Medical Sciences, \\ Tabriz, Iran \\ ${ }^{2}$ Departemnt of Infectious Diseases, Faculty of Medicine, Tabriz University of Medical \\ Sciences, Tabriz, Iran \\ ${ }^{3}$ Departemnt of Clinical Pharmacy, Faculty of Pharmacy, Tabriz University of Medical \\ Sciences, Tabriz, Iran \\ *Corresponding author
}

\section{KEYWORDS}

Respiratory infections,

Vitamin D,

Nutrition,

Outcome

\section{A B S T T R A C T}

To determination of serum level of vitamin $\mathrm{D}$ in hospitalized patients with respiratory infections in infectious disesase ward of Tabriz. In a descriptive-analytical study that performed in Department of infectious diseases of Tabriz on patients with acute respiratory disease, serum level of vitamin $\mathrm{D}$ in hospitalized patients with respiratory infections in infectious disease ward of Tabriz evaluated. In this study, 50 admitted patients with respiratory infections and 50 healthy persons evaluated. Mean age of patients in case group was $61.66 \pm 18.23$ and in control group was $58.80 \pm 12.89$ year $(\mathrm{P}=0.368) .34$ of patients in case group and 30 persons of control group were male $(\mathrm{P}=0.405)$. Mean Vitamin $\mathrm{D}$ level in case group patients was $10.82 \pm 16.85$ and in control group persons was $25.58 \pm 13.98$ year $(\mathrm{P}=0.082)$. 36 of patients had acute pneumonia, 7 of them had TB, 5 of them had exacerbation of COPD and 2 of them had acute tracheobronchitis. 16 of patients had Impaired consciousness. Mean the activity in case group patients was $31.09 \pm 59.32$ hour and the activity in control group persons was $57.69 \pm 54.27$ hour and mean exposure to light in case group patients was $16.55 \pm 19.67$ hour and the exposure to light in control group persons was $11.29 \pm 7.92$ hour. Significant liner correlation was not found between the activity and exposure to light in the studied patients. Significant liner correlation was not found between the Vitamin D level with Consumption of Milk, Yogurt, Butter, Cheese, Bread, Fish, Neat and Eggs in the studied patients and significant direct liner correlation was not found between the Vitamin D level with consumption of hen in the studied patients. According to studies, in general it can be said that, the role of vitamin D in improving pulmonary tuberculosis and other respiratory infections has been demonstrated in cellular and molecular level. But it seems, Geographic region for the presence or absence of the sun, Medicinal doses of vitamin D, Serum levels of vitamin D, the immunity and nutritional status of patients, the presence of comorbidities and other factors have an effective role in the efficacy of vitamin D in the development and exacerbation of respiratory infections. 


\section{Introduction}

Vit-D is the steroid hormone precursor which is responsible for calcium regulation and skeletal health (1). Vit-D was for the first time used for the treatment of rickets. It has been found out that Vit-D is obtained through two separate ways from limited resources and photochemical function of ultraviolet light of the sun in the skin (2). In spite of the availability of Vit-D in this way, vitamin $\mathrm{D}$ deficiency is common. Ultraviolet light (UV) is absorbed by the ozone layer in the atmosphere and therefore the levels of UVB differ by height and season (2). The moderate and high areas where the level of UV in the cold seasons is not enough for the synthesis of vitamin $\mathrm{D}$ for six months are known as the Vit-D winters (2). Today, it is known that Vit D not only has bone functions but also has other roles such as the key role in regulating the immune system and sensitivity to different infections and autoimmune conditions (1-10).

Vit-D receptor and 1-alpha hydroxylase (the enzyme required for the conversion of Vit-D to its active form) are in the immune system cells including the circulating mononuclear cells. Vit-D regulates the expression of endogen antimicrobial peptides in human cells and consequently leads to the potential role of Vit-D in the regulation of the immune response to different infectious diseases. These findings reflect the need for further studies on Vit-D supplements and clinical outcomes of special diseases so as to prove the non-skeletal function of vitamin D (1).

Although numerical definitions differ, Vit-D deficiency is confirmed when the level of Vit-D $25(\mathrm{OH})$ is lower than $20 \mathrm{ng} / \mathrm{mL}(50$ $\mathrm{nM})$. Moreover, when the level of Vit-D is higher than or equal to $30-32 \mathrm{ng} / \mathrm{mL}$ (75-80 $\mathrm{nM})$ it is considered adequate. There is an inverse relationship between the level of
Vit-D and PTH. Hyperglycemia and Vit-D toxicity occur when the level of Vit-D is equal to or higher than $150 \mathrm{ng}(357 \mathrm{nM})$. Urolithiasis and renal failure are the chronic outcomes of an increase in serum Vit D level (2). Results of epidemiological studies indicate that there is a relationship between Vit-D deficiency and increased bladder tumor, breast cancer, colon tumor, ovarian cancer, rectum, autoimmune diseases (e.g. Multiple Sclerosis, Crohn's disease, and DM-I) and infectious diseases (11-16).

Recently, results of epidemiological studies have proved the relationship of seasons with serum Vit-D level and outbreak of infectious diseases such as septic shock, respiratory infection and influenza (1). The relationship between Vit-D deficiency and infectious diseases was discovered a hundred years ago as the effect of Vit-D deficiency on tuberculosis was discovered. Recent studies have confirmed the relationship of active tuberculosis and immeasurable levels of VitD $25(\mathrm{OH})(2)$. In other studies, the Vit-D supplement led to acceleration of recovery from tuberculosis and inflammatory responses (3, 4). Moreover, the useful contributions of Vit-D on the treatment of viral and bacterial (gram positive and gram negative) infections (1-7) are also acknowledged. However, there is limited information about the effects of Vit-D on other diseases such as fungus, protozoa, and parasites (16-20). The present study was conducted due to the aforementioned role of Vit-D level in viral and bacterial infections and even the severity and mortality of community-acquired pneumonia (CAP) and because of the contribution of Vit-D to the improvement of infectious diseases (21-23). The objective of the present research $i$ to study the serum Vit-D level in pulmonary infections and examine the related possible factors. If positive results are obtained, this study can pave the way for future adjunctive 
therapy studies that use Vit-D to treat infections and can show the effectiveness of Vit-D for the prevention of infectious diseases.

\section{Materials and Methods}

In a descriptive analytical study which was carried out in the infectious diseases department of Tabriz University on patients with pulmonary infections, the serum Vit-D level was measured in patients hospitalized with pulmonary infections in the infectious diseases centers of Tabriz. The possible factors associated with the serum Vit-D level were also examined.

In this study, all of the patients who were definitively diagnosed with pulmonary infections (whether acute or chronic) and were admitted in the infectious diseases centers of Sina and Imam Reza hospitals were selected for the study using the convenience sampling method and were included after meeting the inclusion criteria. Upon hospitalization the level of serum VitD $25(\mathrm{OH})$ was measured by taking $5 \mathrm{cc}$ of blood samples from patients. The relationship of serum Vit-D with possible related factors such as the type of pulmonary infection, nutritional condition, clinical findings and experimental parameters was also examined in patients.

The serum Vit-D level was measured using the CLSA method and the LIAISON kits.

Inclusion criteria included the presence of pulmonary infections while exclusion criteria included intake of Vit-D, chronic renal diseases, heart failure, autoimmune diseases, malignancy, consumption of immunosuppressive drugs, receiving chemotherapy, pulmonary edema, pulmonary embolism, and inadequate information about the patient.

\section{Ethical Considerations}

In this study no additional or immoral intervention took place for patients. All of the patients' information will remain confidential and each of the methods used in this research such as -graphies, experiments, and treatments were conducted based on academic procedures. No additional expense was imposed on patients for determining the level of serum Vit-D and informed consent of all patients was also obtained.

\section{Statistical Analysis}

Research results were subjected to statistical analysis and were expressed as mean \pm standard deviation as well as frequency (\%). SPSS 16 was used for the purpose of statistical analysis. In the entire study for $\mathrm{p}<0.05$ the results were considered to be statistically significant. In order to study the possible relationship between serum Vit-D level and research variables the required statistical tests and analyses were conducted based on type of variables.

\section{Results and Discussion}

In this study, 50 patients that were hospitalized with pulmonary infections along with 50 healthy individuals were examined. The following results were obtained:

The mean age of patients in the experimental group and control group was $61.66 \pm 18.23$ and $58.80 \pm 12.89$ years, respectively $(\mathrm{P}=0.368)$.

Of the whole participants, 34 patients were classified in the experiment group and 30 healthy individuals (men) were classified in the control group $(\mathrm{P}=0.405)$. The mean level of Vit-D in patients in the experimental and 
control groups was $19.82 \pm 16.85$ and $25.58 \pm 13.98$, respectively.

In this study, 36 suffered from acute pneumonia, 7 suffered from TB, 5 were diagnosed with intensified COPD and 2 were diagnosed with acute tracheobronchitis.

Moreover, 34 patients were conscious while 16 had consciousness disorders. The mean level of Vit-D in conscious patients and patients with consciousness disorders was $14.69 \pm 11.92 \quad$ and $18.07 \pm 14.17$, respectively $(\mathrm{P}=0.383)$.

Demographic parameters and vital signs of the patients in case group was shown in Table 1 . The mean activity of participants in the experimental and control groups was $31.09 \pm 59.32$ and $57.69 \pm 54.27$ hours a week, respectively.

The activity of participants in the experimental group was significantly lower than those in the control group $(\mathrm{P}=0.021)$. The mean level of exposure to light in members of the experimental and control groups was $16.55 \pm 19.67$ and $11.29 \pm 7.92$ hours a week, respectively $(\mathrm{P}=0.108)$. Two of the male and two of the female patients also died.

The mean level of Vit-D in the living and dead patients was $16.26 \pm 12.92$ and $10.23 \pm 7.78$, respectively $(\mathrm{P}=0.365)$. Table 2 and table 3 shows the laboratory finding of patients. Table 4 shows the nutrition intake for patients of the two groups per week.

The relationship of Vit-D level with the level of activity $(\mathrm{P}=0.109)$ and exposure to light $(\mathrm{P}=0.065)$ was not a significant linear relationship. A significant linear relationship was observed between the level of Vit-D in patients and consumption of chicken by patients $(p=0.026$ and $r=0.236)$. However, the level of Vit-D did not have a significant linear relationship with the intake of other foods.

Moreover, no significant linear relationship was also observed between Vit-D levels in patients and corresponding experimental parameters.

In a study, the level of Vit-D in patients with pulmonary infections and the relationship of Vit-D level with demographic parameters, experimental parameters and nutritional parameters of the patients were studied. A comparison was also made between the results of healthy individuals in the control group and the experimental group. It was found out that although the level of Vit-D was $19.82 \pm 16.85$ in the experimental group and was $25.58 \pm 13.98$ in the control group, no significant difference was observed between the two groups $(\mathrm{P}=0.078)$. This lack of significant difference can be ascribed to the low number of samples under study.

In a study by Sita-Umsden et al., which was carried out on 178 patients with tuberculosis, the level of Vit-D in these patients and the control group was measured. It was stated that the mean level of Vit- $\mathrm{D}_{3}$ in the experimental group was significantly lower than the control group $(\mathrm{P}=0.001)$. Moreover, the diet and degree of exposure to sunlight were similar in the experimental and control groups. The researchers concluded that in patients with tuberculosis other factors are associated with Vit- $\mathrm{D}_{3}$ deficiency (6). In our study no difference was observed between the diet and level of exposure to light in the experimental and control groups. Although the level of Vit- $\mathrm{D}_{3}$ in the experimental group (patients) was lower than the control group (of the 7 patients with tuberculosis one had a normal Vit-D level, one suffered from inadequate Vit-D, and the rest were diagnosed with Vit- $\mathrm{D}_{3}$ deficiency), the 
Int.J.Curr.Res.Aca.Rev.2016; 4(4): 234-247

difference was not statistically significant which can be ascribed to the low number of samples. In a study by Sasidaharan et al., which was conducted on 35 patients with tuberculosis, the mean level of $\mathrm{Vit}-\mathrm{D}_{3}$ in patients with tuberculosis was significantly lower than patients in the control group $(\mathrm{P}=0.005)$. Moreover, in this study the level of Vit-D $\mathrm{D}_{3}$ was lower than $9 \mathrm{ng} / \mathrm{ml}$ in 16 participants $(45.71 \%)(23)$.

Table.1 Demographic parameters and vital signs of patients between two groups

\begin{tabular}{cccc}
\hline & \multicolumn{2}{c}{ Sex } & P \\
\hline Age & $61.31 \pm 16.61$ & $58.31 \pm 14.20$ & 0.363 \\
Height & $169.50 \pm 7.16$ & $160.81 \pm 7.30$ & $<0.001$ \\
Weight & $70.18 \pm 11.76$ & $71.31 \pm 17.56$ & 0.788 \\
BMI & $24.39 \pm 3.60$ & $27.26 \pm 4.88$ & 0.024 \\
Systolic Blood Pressure & $121.44 \pm 23.55$ & $108.33 \pm 15.55$ & 0.056 \\
dyastolic Blood Pressure & $74.38 \pm 9.93$ & $70.00 \pm 8.45$ & 0.148 \\
Heart Rate & $90.69 \pm 18.19$ & $91.33 \pm 12.89$ & 0.902 \\
Respiratory Rate & $26.38 \pm 7.47$ & $26.27 \pm 6.24$ & 0.961 \\
Body Temperature & $37.57 \pm 0.87$ & $37.55 \pm 0.84$ & 0.924 \\
\hline
\end{tabular}

Table.2 Laboratory finding of patients between two genders

\begin{tabular}{|c|c|c|c|}
\hline & \multicolumn{2}{|c|}{ Sex } & \multirow{2}{*}{$\mathrm{P}$} \\
\hline & Male & Female & \\
\hline WBC & $15810.30 \pm 17719.31$ & $11621.88 \pm 6843.66$ & 0.368 \\
\hline $\mathrm{Hb}$ & $12.93 \pm 2.63$ & $11.20 \pm 1.86$ & 0.023 \\
\hline $\mathrm{MCV}$ & $84.61 \pm 8.33$ & $83.64 \pm 6.53$ & 0.704 \\
\hline PLT & $256.85 \pm 147.95$ & $260.81 \pm 139.70$ & 0.929 \\
\hline AST & $37.14 \pm 24.75$ & $30.21 \pm 20.02$ & 0.386 \\
\hline ALT & $27.87 \pm 26.03$ & $24.50 \pm 12.18$ & 0.653 \\
\hline ALP & $229.96 \pm 128.30$ & $242.38 \pm 137.12$ & 0.787 \\
\hline $\mathrm{LDH}$ & $581.60 \pm 169.98$ & $402.13 \pm 123.15$ & 0.016 \\
\hline CPK & $367.73 \pm 857.59$ & $100.67 \pm 75.14$ & 0.606 \\
\hline $\mathrm{Ca}$ & $8.35 \pm 0.90$ & $8.65 \pm 1.19$ & 0.518 \\
\hline Alb & $3.25 \pm 0.45$ & $3.18 \pm 1.35$ & 0.889 \\
\hline Protein & $6.10 \pm 1.08$ & 6.70 & 0.628 \\
\hline ESR & $49.05 \pm 24.55$ & $56.46 \pm 41.65$ & 0.524 \\
\hline BUN & $27.84 \pm 27.95$ & $20.54 \pm 10.47$ & 0.351 \\
\hline $\mathrm{Cr}$ & $1.18 \pm 0.28$ & $1.09 \pm 0.46$ & 0.498 \\
\hline $\mathrm{Na}$ & $139.52 \pm 3.51$ & $140.00 \pm 2.99$ & 0.637 \\
\hline K & $4.28 \pm 0.41$ & $4.29 \pm 0.56$ & 0.951 \\
\hline $\mathrm{Ph}$ & $7.39 \pm 0.07$ & $7.40 \pm 0.05$ & 0.527 \\
\hline $\operatorname{Pco} 2$ & $37.81 \pm 6.53$ & $38.16 \pm 5.40$ & 0.860 \\
\hline Hco3 & $22.44 \pm 2.59$ & $23.72 \pm 3.47$ & 0.181 \\
\hline O2 SAt. & $84.22 \pm 14.17$ & $246.54 \pm 379.88$ & 0.125 \\
\hline $\mathrm{FiO} 2$ & $26.13 \pm 16.83$ & $30.00 \pm 8.42$ & 0.461 \\
\hline
\end{tabular}


Table.3 Laboratory finding of patients based on Diseases types

\begin{tabular}{cccccc}
\hline \multicolumn{5}{c}{} & \multicolumn{2}{c}{ Type of Diseases } & Acute & P \\
& Acute Pneomany & TB & COPD Exacerbation & Theacobronchitis \\
\hline WBC & $15191.14 \pm 17137.07$ & $11442.86 \pm 6750.52$ & $15140.00 \pm 11805.16$ & $10100.00 \pm 141.42$ & 0.916 \\
Hb & $12.48 \pm 2.52$ & $10.59 \pm 2.01$ & $14.26 \pm 2.29$ & $12.10 \pm 2.12$ & 0.091 \\
MCV & $85.30 \pm 7.69$ & $78.80 \pm 6.91$ & $82.93 \pm 8.84$ & 84.00 & 0.370 \\
PLT & $243.03 \pm 144.39$ & $293.86 \pm 87.29$ & $231.80 \pm 103.60$ & $463.50 \pm 301.93$ & 0.167 \\
AST & $35.16 \pm 23.00$ & $40.86 \pm 26.52$ & $14.67 \pm 6.35$ & 31.00 & 0.436 \\
ALT & $27.73 \pm 24.26$ & $24.86 \pm 16.84$ & $22.00 \pm 13.86$ & 23.00 & 0.967 \\
ALP & $226.23 \pm 145.69$ & $278.57 \pm 80.39$ & $202.67 \pm 24.83$ & - & 0.592 \\
LDH & $537.93 \pm 183.91$ & $588.00 \pm 136.41$ & $309.00 \pm 38.11$ & 543.00 & 0.151 \\
CPK & $418.15 \pm 915.62$ & $81.50 \pm 51.62$ & $60.00 \pm 14.14$ & 99.00 & 0.897 \\
Ca & $8.25 \pm 1.09$ & $8.68 \pm 0.35$ & $9.13 \pm 0.75$ & - & 0.339 \\
Alb & $3.11 \pm 0.98$ & $3.36 \pm 0.49$ & 3.80 & - & 0.691 \\
Protein & $5.95 \pm 0.87$ & 7.60 & - & - & 0.139 \\
ESR & $57.88 \pm 30.13$ & $58.00 \pm 24.43$ & $13.50 \pm 8.54$ & $49.00 \pm 59.40$ & 0.073 \\
BUN & $27.66 \pm 27.00$ & $22.00 \pm 9.35$ & $12.50 \pm 3.54$ & $15.50 \pm 3.54$ & 0.729 \\
Cr & $1.20 \pm 0.36$ & $1.01 \pm 0.24$ & $.97 \pm 0.31$ & $1.15 \pm 0.21$ & 0.461 \\
Na & $139.51 \pm 3.41$ & $139.00 \pm 3.79$ & $141.00 \pm 2.12$ & $141.50 \pm 3.54$ & 0.636 \\
K & $4.27 \pm 0.49$ & $4.39 \pm 0.46$ & $4.16 \pm 0.35$ & $4.45 \pm 0.07$ & 0.808 \\
Ph & $7.40 \pm 0.06$ & $7.37 \pm 0.09$ & $7.39 \pm 0.05$ & $7.47 \pm 0.03$ & 0.260 \\
Pco2 & $37.94 \pm 5.58$ & $38.60 \pm 8.51$ & $40.08 \pm 4.85$ & $29.90 \pm 4.10$ & 0.250 \\
Hco3 & $22.92 \pm 2.25$ & $21.64 \pm 3.78$ & $24.48 \pm 5.15$ & $22.10 \pm 1.56$ & 0.421 \\
O2 SAt. & $138.97 \pm 226.84$ & $96.50 \pm 2.12$ & $94.50 \pm 0.71$ & - & 0.936 \\
FiO2 & $29.25 \pm 16.82$ & $21.00 \pm 0.00$ & $26.60 \pm 8.44$ & 21.00 & 0.683 \\
\hline & & & & &
\end{tabular}

Table.4 Nutrition intake for patients of the two groups per week

\begin{tabular}{|c|c|c|c|}
\hline \multicolumn{4}{|c|}{ Groups } \\
\hline & Case & Control & $\mathrm{P}$ \\
\hline Milk & $610.00 \pm 655.14$ & $366.06 \pm 480.01$ & 0.048 \\
\hline Yogurt & $380.00 \pm 315.71$ & $468.54 \pm 378.88$ & 0.239 \\
\hline Butter & $137.25 \pm 157.43$ & $123.54 \pm 201.88$ & 0.727 \\
\hline Cheese & $48.02 \pm 60.23$ & $39.04 \pm 16.57$ & 0.324 \\
\hline Bread & $3.41 \pm 6.27$ & $2.51 \pm 1.09$ & 0.328 \\
\hline Fish & $83.79 \pm 156.03$ & $106.54 \pm 110.28$ & 0.426 \\
\hline Red Meat & $29.00 \pm 26.14$ & $29.11 \pm 24.37$ & 0.983 \\
\hline Chicken & $19.73 \pm 26.19$ & $15.54 \pm 11.84$ & 0.319 \\
\hline Egg & $103.66 \pm 114.91$ & $62.19 \pm 51.93$ & 0.038 \\
\hline
\end{tabular}


Int.J.Curr.Res.Aca.Rev.2016; 4(4): 234-247

Table.5 Nutrition intake for patients of the Case group based on Diseases types

\begin{tabular}{cccccc}
\hline & & \multicolumn{2}{c}{ Type of Diseases } & & \\
& Acute Pneumonia & TB & $\begin{array}{c}\text { COPD } \\
\text { Exacerbation }\end{array}$ & $\begin{array}{c}\text { Acute } \\
\text { Tracheobronchitis }\end{array}$ & $\mathrm{P}$ \\
\hline Milk & $680.97 \pm 704.72$ & $175.00 \pm 221.74$ & $675.00 \pm 518.81$ & $250.00 \pm 353.55$ & 0.441 \\
Yogurt & $395.48 \pm 311.78$ & $80.00 \pm 113.14$ & $560.00 \pm 395.98$ & $380.00 \pm 254.56$ & 0.172 \\
Butter & $147.00 \pm 156.67$ & $15.00 \pm 30.00$ & $255.00 \pm 179.16$ & 0 & 0.093 \\
Cheese & $51.52 \pm 68.96$ & $42.00 \pm 0.00$ & $30.00 \pm 13.86$ & $42.00 \pm 0$ & 0.920 \\
Bread & $3.73 \pm 7.19$ & $2.13 \pm 1.31$ & $2.75 \pm 0.87$ & $2.50 \pm 0.71$ & 0.957 \\
Fish & $65.05 \pm 84.76$ & 0 & $225.00 \pm 384.06$ & $250.00 \pm 353.55$ & 0.061 \\
Red & $33.19 \pm 27.84$ & $8.50 \pm 1.73$ & $19.00 \pm 20.05$ & $25.00 \pm 14.14$ & 0.280 \\
Meat & $17.45 \pm 24.76$ & $28.00 \pm 24.25$ & $10.25 \pm 2.87$ & $57.50 \pm 60.10$ & 0.148 \\
Chicken & $122.58 \pm 124.06$ & $56.25 \pm 47.32$ & $6.25 \pm 12.50$ & $100.00 \pm 35.36$ & 0.225 \\
Egg & & & & &
\end{tabular}

In our study, the mean level of Vit- $\mathrm{D}_{3}$ in patients with tuberculosis was $18.38 \pm 13.17$. Of the 7 patients with tuberculosis, in 3 patients $(42 \%)$ the level of Vit- $\mathrm{D}_{3}$ was lower than $10 \mathrm{ng} / \mathrm{ml}$, which is similar to the results of the aforementioned study. Jovanovich et al., carried out a study in the University of Colorado (Denver, USA) in 2014 to study the level of Vit-D in patients with CAP (community-acquired pneumonia). The researchers stated that a level of Vit-D that is lower than 37 significantly leads to an increase in the hospitalization of patients with CAP (24).

In a study by Borella et al., (2014) the level of Vit-D was studied in patients and its relationship with infection was also investigated in the patients. The researchers stated that Vit-D acts as an anti-infection factor and the level of Vit-D is low in patients with infection (25).

In this study, the patients showed low levels of vitamin D. In a study by Waters et al., the level of Vit-D was measured in patients with pulmonary infections as well as members of the control group. The researchers stated that the level of $V$ it $-\mathrm{D}_{3}$ in patients with pulmonary infections was significantly lower than the participants in the control group (26). Lakin et al., conducted a study and reported that patients with Vit-D deficiency experience an increase in the risk and severity of the respiratory system infections (27).

Dr. Qurayshi et al., (2013) carried out a study in Harvard University (USA) to examine the level of Vit-D in patients with CAP. The researchers reported that in patients with CAP a Vit-D level below 30 leads to an increase in the risk and severity of infections and duration of hospitalization (28). In this study the level of Vit-D was $19.82 \pm 16.85$ and $25.58 \pm 13.98$ in the experimental and control groups. Moreover, although the level of Vit-D in patients with pulmonary infections was lower than patients of the control group, the difference was not statistically significant. However, in the patients of the experimental group the level of Vit-D deficiency was significantly higher than the healthy participants in the control group $(\mathrm{P}=0.024)$. These results also comply with the results of the above mentioned study.

In women who were receiving Vit-D treatment for the prevention of osteoporosis 
a lower level of HP infections was observed $(1,2)$. Moreover, in other studies a relationship was observed between Vit-D deficiency with bacterial vaginosis in pregnant women (29).

In a study of adult patients who were hospitalized for CAP and who suffered from Vit-D deficiency a higher mortality rate was reported (30). In the present study, the mean level of Vit-D in the living and deceased patients was $16.26 \pm 12.92$ and $10.23 \pm 7.78$, respectively. Although the level of Vit-D in the deceased patients was lower than the living patients, no significant difference was observed between the levels of Vit-D in patients based on mortality $(\mathrm{p}=0.365)$.

In a study the role of Vit-D in the resistance to upper and lower pulmonary infections was studied based on different causes and factors such as viral factors $(1,2)$. In another study the subclinical deficiency of Vit-D was found to be accompanied by severe infections of the lower respiratory tract (31). In a study in Ethiopia the Vit-D deficiency was associated with a 13-fold increase in the risk of pneumonia in children (32).

In a study in Finland it was found out that a wide range of acute respiratory infections are caused by a serum Vit-D 25(OH) level of below $4 \mathrm{ng} / \mathrm{mL}$ (33). Cannell used epidemiological evidence to show that in the cold seasons due to the low production of skin Vit-D seasonal influenza becomes epidemic (34-35).

In a study by Pletz et al., (2014), which was carried out in the infectious diseases department of Jena University of Germany, it was reported that in patients with CAP, Vit-D deficiency increases with an increase in the severity of the disease. Moreover, the Vit-D deficiency was also significantly related to the growth of renal and pulmonary complications in these patients (36). In our study, in spite of the deficiency of Vit-D in the patients, the mean level of AST in patients with CAP was $27.73 \pm 24.26$. In other patients the level of renal enzymes was normal and no hepatic complication was observed. This finding was in contrast to the findings of the aforementioned research. In a study by Ren et al., (2013) in the Jiangsu University of China, the level of Vit-D was measured in patients with CAP and it was reported that Vit-D is strongly related to the severity of CAP (37).

Finally, clinical and genetic evidence suggest that Vit-D plays a role in the regulation of $\mathrm{HIV}$ infection $(1,2)$. In a recent study that was conducted on HIV positive patients in Iran, it was found out that $86.7 \%$ of patients were suffering from Vit-D deficiency. In that research, the serum Vit-D level was associated with factors such as the intake of Vit-D, duration of exposure to sunlight, PTH level, and daily consumption of calcium (38). Various studies have reported the high level of Vit-D deficiency in the Iranian society. These studies have introduced factors such as age, gender, BMI, air pollution, calcium intake, Vit-D intake, exposure to sunlight and renal performance as the possible risk factors (39, 40). In our study the relationship of Vit-D levels in patients with age, gender, BMI and exposure to sunlight was not a significantly linear relationship.

In spite of new advances in understanding the non-classic function of Vit-D, little information is available about the clinical improvement of diseases (1). In addition, by examining the existence of a statistically significant relationship between Vit-D3 levels and season it was stated that there is a statistically significant relationship between tuberculosis and Vit- $\mathrm{D}_{3}$ level in summer $(\mathrm{p}=0.007)$ and autumn $(\mathrm{p}=0.02)$. However, 
the aforementioned relationship was not significant in winter $(\mathrm{p}=0.08)(26)$.

In the study by Rocket (1998) it was found out that active Vit- $\mathrm{D}_{3}$ inhibits the growth of mycobacterium tuberculosis in macrophagelike human cells. He also referred to the possible role of Vit-D in the resistance to mycobacterium tuberculosis in the hosts (23).

Sasidaharan et al., (2002) studied 35 patients with sputum smear positive pulmonary and extra-pulmonary TB and 16 healthy individuals. A significant statistical difference $(\mathrm{P}<0.005)$ was observed between the levels of Vit-D in the health participants $($ mean $=19.5 \mathrm{ng} / \mathrm{ml})$ and patients (mean $=10.7 \mathrm{ng} / \mathrm{ml}$ ). In 6 of the 35 patients the level of Vit-D was below $9 \mathrm{ng} / \mathrm{ml}$ and in none of the healthy individuals the level of Vit-D was lower than $9 \mathrm{ng} / \mathrm{ml}$ (41).

Moreover, patients with a lower Vit-D level used adequate exposure to sunlight but had a low Vit-D intake. The researchers therefore concluded that when the level of 25-hydroxy vitamin $\mathrm{D}$ is lower than $9 \mathrm{ng} / \mathrm{ml}$ tuberculosis is activated while a reduction in Vit-D may be asymptotic. However, demonstration of symptoms of a reduction in Vit-D reflects a severe decrease in this vitamin. The levels of phosphorous and calcium cannot predict the reduction in Vit-D (41).

In the research by Douglas et al., in Birmingham (England) it was found that Vit-D may play an important role in the immunologic resistance to tuberculosis (42). Wilkinson et al., also carried out a study which revealed that sensitivity to tuberculosis is affected by environmental conditions and genetic factors in the host after infection by mycobacterium tuberculosis. The Vit-D metabolism leads to the activation of macrophages and limitation of intercellular growth of mycobacterium tuberculosis. The Vit-D deficiency also leads to the activation of tuberculosis (43).

Douglas et al., conducted a study in England which showed that Vit-D plays a significant role in the immunologic resistance to tuberculosis (44). Vit-D activates macrophages to limit the intercellular growth of mycobacterium tuberculosis. On the other hand, Vit-D deficiency also activates tuberculosis (45).

The study by Wejse et al., in India revealed that the daily consumption of Vit-D (100000iu) made no changes in TB scare and sputum smear of patients (21). However, Nursyma et al., carried out a study in England which showed that patients receiving Vit-D supplements experienced radiological improvement (22). Another study by Shapria et al., resulted in similar results. In this study the effect of Vit-D (100000iu) on the treatment was not significant (46).

In the examination of the possible relationship between Vit-D deficiency and sensitivity to tuberculosis as well as the relationship between prevalence of tuberculosis and seasonal condition of Vit-D in different countries such as Europe, North America, Scandinavia, and Hong Kong it was found out that the serum Vit-D level in healthy individuals varies by season. Moreover, it was concluded that the serum Vit-D level is higher in TB patients compared to healthy individuals. The difference is more significant in countries with low levels of Vit-D (47).

In a study by Chandra et al., (2004) in the tuberculosis research center of India it was found that $10 \mathrm{ng} / \mathrm{ml}$ of $\mathrm{Vit}^{-\mathrm{D}_{3}}$ leads to a considerable increase in the phagocytosis of macrophages for the living mycobacterium tuberculosis in normal humans. Moreover, Vit- $\mathrm{D}_{3}$ increases the apoptosis of 
mononuclear cells in peripheral blood of TB positive patients (26). Shortage of Vit-D is also associated with the increased risk of tuberculosis infection.

In an in vitro study by Waters et al., (2004) it was found out that Vit-D 25(OH) adds to the severity of mycobacterium tuberculosis apoptosis by increasing the generation of NO (48). Lang et al., (2013) carried out a study in the lung unit of Brigham University of Bolton (USA) and studied the level of Vit-D in the hospitalized patients. The researchers stated that a Vit-D level below 30 was associated with increased mortality while a Vit-D level of below 15 was associated with CAP (49).

The mean level of Vit-D in the living patients and dead patients was $16.26 \pm 12.92$ and $10.23 \pm 7.78$, respectively. No significant difference was observed between the levels of Vit-D in patients based on mortality $(\mathrm{P}=0.365)$. In a study by Charan et al., (2012) in the Rajkot University of India the level of Vit-D was examined in the participants. The researchers reported that patients with respiratory tract infections showed a lower Vit-D level as compared to the participants of the control group (50). In another study by Choudhart et al., the results of treatment of patients with severe pneumonia with Vit-D were studied. It was stated that Vit-D treatment leaves no significant effect on the improvement and prognosis of patients (51). Sudfeld et al., (2013) carried out a study in the epidemiology department of Brigham University of Massachusetts (USA) and stated that Vit-D deficiency (Vit-D $<20$ ) is significantly related to the development of TB (52).

\section{Conclusion}

In sum, it can be said that the role of Vit-D in the improvement of tuberculosis and other pulmonary infections is proved at the cellular and molecular levels. However, it seems that the geographical area (the presence or absence of sunlight) Vit-D dosage, serum Vit-D level, immunity level, nutritional status of patients, presence of complications, and other factors play an important role in the effectiveness of Vit-D for the development and advancement of pulmonary infections. The mean level of Vit-D in the living and deceased patients was $16.26 \pm 12.92$ and $10.23 \pm 7.78$, respectively. No significant difference was also observed between the levels of Vit-D in patients based on mortality.

\section{Suggestions}

It is recommended to carry out more studies with larger samples in different climatic regions of our dear country Iran. It is also recommended to carry out separate studies on patients and healthy individuals based on seasonal conditions, the level of activity and the extent of exposure to light.

The effect of Vit-D deficiency on other infectious disease except for pulmonary infections shall be also examined.

It is recommended to study the polymorphism of genes involved in the synthesis of Vit-D and the relationship between the polymorphism and some infections.

The degree of exposure to light in different seasons and the relationship of exposure to light with Vit-D level and development of some infections shall be investigated separately as well.

Considering the results of various studies that report the involvement of Vit-D deficiency in the development of various infections, it is recommended to conduct 
Int.J.Curr.Res.Aca.Rev.2016; 4(4): 234-247

interventional studies based on the administration of Vit-D supplements for the treatment of infections (including pulmonary infections).

It is also suggested to study the effect of Vit$\mathrm{D}$ on the improvement of infections and a decrease in the hospitalization period and mortality of patients.

\section{Acknowledgement}

This work was supported fully by Infectious and Tropical Diseases Research Center, Tabriz University of Medical Sciences, Tabriz, Iran. Also, this is a report of a database from MD thesis of Mrs. Fatemeh Ravanbakhs Ghavghani registerd in Faculty of Medicine, Tabriz University of Medical Sciences, Tabriz, Iran.

\section{References}

1.A.Ymashchikov,N.Desai,H.Blumbrg,T.Zie gler,V.Tangprcha. 2009 Vitamin D for Treatment and Prevention of Infectious Diseases: A Systematic Review of Randomized Controlled Trials. Endocr Pract. 15(5):438-49.

2.J.H. White.2008. Vitamin D Signaling, Infectious Diseases, and Regulation of Innate Immunity. J.Infection and immunity. 3837-3843.

3.K.Kelland.2012. "Sunshine" vitamin D found to speed tuberculosis recovery.

4.A. K. Coussensa. R. J. Wilkinsona,b. Y. Hanifac. V. Nikolayevskyyd, et al., 2012. Vitamin D accelerates resolution of inflammatory responses during tuberculosis treatment. $\mathbf{J}$ PNAS.1-6.

5.Mandell GL, Bennet JE, Dolin R. Principles and practice of infectious diseases. Fifth edition, 2000; 4: 25762608.
6.Sita-Lumsden A, Swaminathan R. Sun related vitamin $\mathrm{D}$ deficiency and reactivation of tuberculosis. Www.thoraxjnl.com, 1998.

7.Tan TQ, Mason EO Jr, Barson WJ, Wald ER, Schutze GE, Bradley JS. (1998). Clinical characteristics and outcome of children with pneumonia attributable to penicillin-susceptible and penicillin-nonsusceptible Streptococcus pneumoniae. Pediatrica, 102, 1369-1375.

8. Olaechea PM, Ulibarrena MA, AlvarezLerma F, Insausti J, Palomar M. (2003). Factors related to hospital stay among patients with nosocomial infection acquired in the intensive care unit. Infect Control Hosp Epidemiol, 24, 207-213.

9.Parsa Yekta Z, Rezai pour A, Faghihzadeh S, Rassouli M. (2001). The survey of incidence of nosocomial pneumonia related to Aspiration in intensive care units. Hayat, 7, 4-13.

10.Rello J, Paiva JA, Baraibar J, Barcenilla F, Bodi M, Castander D. (2001). International Conference for the Development of Consensus on the Diagnosis and Treatment of Ventilator-associated Pneumonia. Chest, 120, 955-970.

11.Leone M, Bourgoin A, Giuly E, Antonini F, Dubuc M, Viviand X, Albanèse J, Martin C. (2002). Influence on outcome of ventilator-associated pneumonia in multiple trauma patients with head trauma treated with selected digestive decontamination. Crit Care Med, 30, 1741-1746.

12.Shamszade Amiri M. (2006). Influence on outcome of ventilator-associated pneumonia in multiple trauma patients with head trauma treated with selected digestive 
decontamination. Ann Intern Med, 74, 992-994.

13.Seguin $\mathrm{P}$, Tanguy M, Laviolle B, Tirel O, Malledant Y. (2006). Effect of oropharyngeal decontamination by povidone-iodine on ventilatorassociated pneumonia in patients with head trauma. Crit Care med, 34, 1514-1519.

14.Chan TYK.Vitamin D deficiency and susceptibility to Tuberculosis. Calcified tissue international, 2000; 66(6): 476-80.

15.Waters WR, Nonnecke BJ. Mycobacterium bovis bacilli Calmette-Guerin vaccination of cattle : activation of bovine CD4 \pm and gamma delta TCR \pm cells and modulation by 1,25 dihydroxy vitamin D3 . Tuberculosis (Edinb), 2003; 83(5):287-97.

16.Liuw, Zhang CY. A case - control study on the vitamin D receptor gene polymorphisms and susceptibility to pulmonary tuberculosis.Zhonghua Liu xing Bing Xuezazhi, 2003 ;24 (5):389-92.

17.Martineau AR, Wilkinson KA, Newton SM, Floto RA, Norman AW, Skolimowska $\mathrm{K}$, et al., IFNgammaand TNF-independent vitamin Dinducible human suppression of mycobacteria:the role of cathelicidin LL-37. J Immunol 2007;178(11): 7190-8.

18.Chan TY. Seasonal variations in vitamin D statues and the incidence of tuberculosis in different countries. Respiration 1999; 66(2): 196.

19.Briffa J. Vitamin D helps to combat tuberculosis, flu and other infections.

20.http://www.drbriffa.com/2009/06/22/ vitamin-dhelps-to-combattuberculosis-flu-and-otherinfections/

21.Wejse C, Gomes VF, Rabna P, Gustafson $\mathrm{P}$, Aaby P, Lisse IM, et al., Vitamin
D as supplementary treatment for tuberculosis: a double-blind, randomized, placebo-controlled trial. Am J Respir Crit Care Med 2009; 179(9): 843-50.

22.Nursyam EW, Amin Z, Rumende CM. The effect of vitamin $D$ as supplementary treatment in patients with moderately advanced pulmonary tuberculous lesion. Acta Med Indones 2006; 38(1): 3-5.

23-Rocket A. Tuberculosis and vitamin D deficiency. www.thoraxjnl.com, 1998.

24.Jovanovich AJ, Ginde AA, Holmen J, Jablonski K, Allyn RL, Kendrick J, Chonchol M(2014). Vitamin D level and risk of communityacquired pneumonia and sepsis. Nutrients, 6(6),2196-205. doi: 10.3390/nu6062196.

25.Borella E, Nesher G, Israeli E, Shoenfeld Y(2014). Vitamin D: a new antiinfective agent? Ann $N Y$ Acad Sci,1317,76-83. doi: 10.1111/nyas. 12321. Epub 2014 Mar 4.

26.Chandra G ,Selvaraj P. Effect of vitamin D3 on phagocytic potential of macrophages with live Mycobacterium tuberculosis and lymphoproliferative response in pulmonary tuberculosis. J Clin Immunol, 2004; 24(3):249-57.

27.Larkin A, Lassetter J(2014). Vitamin d deficiency and acute lower respiratory infections in children younger than 5 years: identification and treatment. J Pediatr Health Care, 28(6),572-82. doi: 10.1016/j.pedhc. 2014.08.013. Epub 2014 Oct 18.

28.Quraishi SA, Bittner EA, Christopher KB, Camargo CA Jr(2013). Vitamin D status and communityacquired pneumonia: results from the third National Health and Nutrition Examination Survey. PLoS One, 
Int.J.Curr.Res.Aca.Rev.2016; 4(4): 234-247

8(11),e81120.

10.1371/journal.pone.0081120.

eCollection 2013.

29.L. Barclay. 2010. Vitamin D Deficiency Linked to Bacterial Vaginosis. J. Nutrition. 139:1157-1161.

30.W.Blackwell.2011.Vitamin D Deficiency in Pneumonia Patients Associated with Increased Mortality.J. resoirology.

31.Wayse, V., A. Yousafzai, K. Mogale, and S. Filteau. 2004. Association of subclinical vitamin D deficiency with severe acute lower respiratory infection in Indian children under $5 \mathrm{y}$. Eur. J. Clin. Nutr. 58:563-567.

32.Muhe, L., S. Lulseged, K. E. Mason, and E. A. F. Simoes. 1997. Casecontrol study of the role of nutritional rickets in the risk of developing pneumonia in Ethiopian children. Lancet 349:1801-1804.

33.Lim, W.-C., S. B. Hanauer, and Y. C. Li. 2005. Mechanisms of disease: vitamin $\mathrm{D}$ and inflammatory bowel disease. Nat. Clin. Pract. Gastroenterol. Hepatol. 2:308-315.

34.Cannell, J. J., R. Vieth, J. C. Umhau, M. F. Holick, W. B. Grant, S. Madronich, C. F. Garland, and E. Giovannucci. 2006. Epidemic influenza and vitamin D. Epidemiol. Infect. 134:1129-1140.

35.Cannell, J. J., M. Zasloff, C. F. Garland, R. Scragg, and E. Giovannucci. 2008. On the epidemiology of influenza. Virol. J. 5:Art 29.

36.Pletz MW, Terkamp C, Schumacher U, Rohde G, Schütte H, Welte T, Bals R; Capnetz-Study Group (2014). Vitamin D deficiency in community-acquired pneumonia: low levels of 1,25(OH)2 D are associated with disease severity. Respir Res, 15,53. doi: 10.1186/1465-9921-1553.
37.Ren J, Sun B, Miao P, Feng X(2013). Correlation between serum vitamin D level and severity of community acquired pneumonia in young children. Zhongguo Dang Dai Er Ke Za Zhi,15(7),519-21.

38.M.Etminani-Esfahani ,H. Khalili , N. Soleimani, S. Jafari , A. Abdollahi, Z. Khazaeipour , K. Gholami .2012. Serum vitamin $\mathrm{D}$ concentration and potential risk factors for its deficiency in HIV positive individuals. J.Curr. HIV Res. 10(2):165-70.

39.S. Hashemipour, B Larijani, H. Adaibi et al., 2004. Vitamin D deficiency and causative factors in the population of Tehran. J. BMC Public Health; 4:38.

40.F. Hosseinipanah, S. Hashemipour, M Heibatollahi et al., 2010. The effects of air pollution on vitamin $\mathrm{D}$ status in healthy women: A cross section of study. J. BMC Public Health; 10:519.

41.Sasidharan PK, Rajeer E, Vijayakumari V. Tuberculosis and vitamin D deficiency. $\mathrm{J}$ Assoc physicians India, 2002; 50:554-80.

42.Douglas AS, Ali S,Bakhshiss.Does vitamin $D$ deficiency account for ethnic differences in tuberculosis seasonality in the UK. Ethn health, 1998; 3(4):247-53.

43.Wilkinson RJ, Lewelyn M . Influence of vitamin $\mathrm{D}$ deficiency and vitamin $\mathrm{D}$ receptor polymorphisms on tuberculosis among Gujarati Asians in west London: a case - control study. Lancet, 2000, 19; 355(9204):618-21.

44.Martineau AR, Honecker FU, Wilkinson RJ, Griffiths CJ. Vitamin D in the treatment of pulmonary tuberculosis. J Steroid Biochem Mol Biol 2007; 103(3-5): 793-8.

45.Douglas AS, Ali S, Bakhshi SS. Does vitamin $\mathrm{D}$ deficiency account for 
ethnic differences in tuberculosis seasonality in the UK? Ethn Health 1998; 3(4): 247-53.

46.Wilkinson RJ, Liewelyn M. Influence of vitamin $\mathrm{D}$ deficiency and vitamin $\mathrm{D}$ receptor polymorphisms on tuberculosis among Gujarati Asians in west London: a case- control study. Lancet 2000; 355(9204): 61821.

47.Chan TYK. Seasonal variations in vitamin $D$ status and the incindence of tuberculosis in different countries. Respiration (international journal of thoracic medicine), 1999; 66 (2): 196.

48. Waters WR, Palmer MV. Mycobacterium bovis infection of vitamin $\mathrm{D}$ deficient NOS2-/- mice. Microb Pathog, 2004; 36(1):7-11.

49.Lange N, Litonjua AA, Gibbons FK, Giovannucci E, Christopher KB. 8-Lange N, et al(2013). Prehospital vitamin D concentration, mortality, and bloodstream infection in a hospitalized patient population.
Am J Med, 126 (7), 640.e19-27. doi: 10.1016/j.amjmed.2012.12.014.

50.Charan J, Goyal JP, Saxena D, Yadav $\mathrm{P}(2012)$. Vitamin D for prevention of respiratory tract infections: A systematic review and meta-analysis. $J$ Pharmacol Pharmacother, 3(4), 300-3. doi: 10.4103/0976$500 X .103685$.

51.Choudhary N, Gupta P(2012). Vitamin D supplementation for severe pneumonia--a randomized controlled trial. Indian Pediatr, 49(6),449-54. Epub 2011 Aug 15.

52.Sudfeld CR, Giovannucci EL, Isanaka S, Aboud S, Mugusi FM, Wang M, et al (2013). Vitamin D status and incidence of pulmonary tuberculosis, opportunistic infections, and wasting among HIV-infected Tanzanian adults initiating antiretroviral therapy. J Infect Dis,207(3),378-85. doi: 10.1093/infdis/jis693. Epub 2012 Nov 16.

\section{How to cite this article:}

Zhinous Bayatmakoo, Fatemeh Ravanbakhs Ghavghani and Haleh Rezaee. 2016. Determination of serum level of Vitamin D in hospitalized patients with respiratory infections in infectious disesase wards of Tabriz. Int.J.Curr.Res.Aca.Rev.4(4): 234-247.

doi: http://dx.doi.org/10.20546/ijcrar.2016.404.029 